\title{
Review: early mobilisation may be better than bed rest for medical conditions and after surgery
}

Allen C, Glasziou P, Del Mar C. Bed rest: a potentially harmful treatment needing more careful evaluation. Lancet 1999 Oct 9;354:1229-33.

\section{QUESTION: Is bed rest as effective as early mobilisation for patients with medical conditions or after health care procedures?}

\section{Data sources}

Randomised controlled trials (RCTs) were identified by searching Medline and the Cochrane Library (1966 to June 1998) with terms related to bed rest (bed rest, bedrest, recumben [with various endings], expectant, and rest) and its opposite (early ambulat [with various endings], early activation, and early discharge). Personal files and bibliographies of relevant studies and review articles were also checked.

\section{Study selection}

Studies were selected if groups were studied in the same environment; treatments were the same except for the amount of bed rest prescribed; and treatments included drugs, surgery, or physical therapy but not education or advice.

\section{Data extraction}

Data were extracted on procedures (lumbar puncture, spinal anesthesia, radiculography, cardiac catheterisation, skin graft for burns, liver biopsy, fixation of femoral fracture, pressure sore surgery, and ileus after gastric surgery) and conditions (acute low back pain, spontaneous labour, pregnancy induced hypertension with proteinuria, early threatened abortion, uncomplicated myocardial infarction, pulmonary tuberculosis, rheumatoid arthritis, and acute infectious hepatitis), ambulatory and bed rest interventions, and outcomes.

\section{Main results}

39 trials of 15 disorders (5777 patients) were included. Data were not pooled because of study diversity. 24 trials evaluated bed rest after medical procedures; only 9 outcomes differed, and all showed worse outcomes for bed rest: nausea after lumbar puncture; severe headache after urological spinal anesthesia; headache after obstetric spinal anesthesia; dizziness after radiculography of the lumbar spine; haematoma, back pain or leg stiffness, any pain, and back pain after cardiac catheterisation; and time to normal bowel function in ileus after gastric surgery. Non-significant trends showed that 7 outcomes favored bed rest and 17 favored early mobilisation.

15 trials evaluated bed rest as a primary treatment; only 8 outcomes differed, and all showed worse outcomes for bed rest: disability at day 1 for acute low back pain; length of first stage of labour, contraction strength, assisted delivery, need for analgesia, and Apgar score at 5 minutes; venous thrombosis after myocardial infarction; and time for recovery after acute infectious hepatitis. Nonsignificant trends showed that 6 outcomes favored bed rest and 16 favoured early mobilisation.

\section{Conclusion}

Bed rest after medical or surgical procedures or for primary treatment of medical conditions may be associated with worse outcomes.
Source of funding: no external funding.

For correspondence: Dr P Glasziou, Centre for General Practice, Graduate School of Medicine, University of Queensland, Herston, Oueensland 4006 Australia. Fax +617 33655442

\section{COMMENTARY}

Allen and colleagues have given a fascinating overview of RCTs that evaluate bed rest as a treatment or prophylactic measure. The study provides evidence to support what clinicians have been doing for several decades-mobilising patients as early as possible. The review has some weaknesses. The trials vary greatly in publication date ( $>30 \mathrm{y}$ time span), and medical norms have also changed over time. For example, 21 days of bed rest was once recommended after myocardial infarction. Furthermore, the authors were unable to pool the data, which is probably why they concluded that they should not assume any efficacy for bed rest and that further studies are necessary to establish whether bed rest is a truly harmful treatment.

Yet there is enough evidence for such conditions as low back pain and myocardial infarction and such procedures as hip surgery to state that bed rest, or at least prolonged bed rest, is harmful. Evidence for the benefit of bed rest is persistently lacking in various obstetric situations, such as multiple pregnancies, threatened abortion, and impaired fetal growth, and is convincing enough to advise against recommending it. ${ }^{12}$ Economic and clinical considerations provide the impetus for shortening the length of bed rest after such cardiac interventions as catheterisation, stenting, ${ }^{3}$ and related procedures. In situations where evidence is still somewhat equivocal, clinicians are left to evaluate each situation carefully, taking into account that mobilisation is probably better than bed rest and is a key component of recovery, rehabilitation, and healthy living in general.

\section{Shmuel Reis, MD Technion Medical School Haifa, Israel}

1 Crowther CA. Hospitalization and bed rest for multiple pregnancy [Cochrane review]. In: the Cochrane Library, Issue 4, 1999. Oxford: Update Software.

2 Gulmezoglu AM, Hofmeyr GJ. Bed rest in hospital for suspected impaired fetal growth [Cochrane review]. In: the Cochrane Library, Issue 4, 1999. Oxford: Update Software.

3 Logemann T, Luetmer P, Kaliebe J, et al. Two versus six hours of bed rest following left-sided cardiac catheterization and meta-analysis of early ambulation trials. Am J Cardiol 1999;84:486-8, A10. 